\title{
Revisitando as origens do ensino de graduação em administração pública no Brasil (1854-1952)
}

\author{
Fernando de Souza Coelho \\ EACH/Universidade de São Paulo \\ Alexandre Mendes Nicolini \\ PPGA/Universidade do Grande Rio
}

\begin{abstract}
A história do ensino de graduação em administração pública no Brasil é retratada por um conjunto de obras/autores que partem da instalação do curso da EBAP-FGV em 1952 como o marco zero. Contudo, pouco se escreveu sobre a pré-história dessa formação acadêmica no país; seus antecedentes carecem de sistematização. O objetivo deste artigo é rever as origens desse ensino para compreender sua evolução e institucionalização na educação superior nacional. Esse esforço contribui para a construção da memória da área de conhecimento de administração no Brasil, em geral, e do seu ensino (e pesquisa), em particular. Baseado em ampla revisão bibliográfica e em uma razoável análise documental, o artigo desvela três momentos nítidos, conexos e sucessivos entre o Segundo Império e o final do Estado Novo que precedem a institucionalização desse curso superior na década de 1950.
\end{abstract}

Palavras-chave: história; ensino de graduação; administração pública; Brasil.

Revisitando los orígenes de los programas de grado en administración pública en Brasil (18541952)

La historia de la educación de grado en administración pública en Brasil se cuenta con un lote de libros/ autores desde la instalación de este curso en EBAP-FGV, marzo 1952. Sin embargo, poco fue escrito sobre la historia temprana de esta formación académica en Brasil. Este artículo tiene como objetivo revisar los orígenes de esta educación para comprender su introducción en el sistema nacional de enseñanza superior. Este tipo de trabajo es importante porque contribuye a la construcción de una memoria de la área de conocimiento de la administración pública en Brasil, y en particular de su enseñanza (y investigación). Basado en una extensa revisión de la literatura y el análisis de documentos, el artículo revela tres momentos claros, relacionados y sucesivos entre el II Imperio y el fin de Estado Novo, que precedió a la institucionalización de este curso de la educación superior en la década de 1950.

Palabras clave: historia; educación universitária; administración pública; Brasil.

http://dx.doi.org/10.1590/0034-76121597

Artigo recebido em 10 jun. 2013 e aceito em 18 dez. 2013.

Rev. Adm. Pública - Rio de Janeiro 48(2):367-388, mar./abr. 2014 
Revisiting the origins of the undergraduate programs in public administration in Brazil (18541952)

The history of undergraduate education in public administration in Brazil is told by a set of books/ authors since the installation of this course at EBAP-FGV in March 1952. However, few words were written about the early history of this academic training in Brazil; its history need systematization. This article aims to review the origins of that education to understand its introducing in national higher education system. This kind of work is important because it contributes for the construction of a memory of public administration knowledge area in Brazil, and particularly of its teaching (and research). Based on an extensive literature review and document analysis, the article reveals three clear, related and successive moments between the II Empire and the end of Estado Novo, which preceded the institutionalization of this higher education course in the decade of 1950.

KEYWORDs: history; undergraduate education; public administration; Brazil.

\section{Introdução}

Que venho eu repetindo (...) em trabalhos, conferências e aulas sobre o ensino de administração pública?

Tenho repetido que o governo, foco central para onde convergem, e onde repercutem, cedo ou tarde, todos os movimentos e ecos das tendências, anseios e desajustamentos sociais, não pode fugir ao imperativo de se afeiçoar às condições cambiantes do mundo. (...) Tenho repetido, finalmente, que entre os meios de ação do Estado, o elemento humano - o pessoal — desempenha papel tão importante que seria ocioso encarecer.

O simples enunciado dessas teses indica, por si só, a necessidade de preparar homens e mulheres para servir o Estado como funcionários públicos. Mas é quando se contrastam as funções relativamente simples do Estado antigo com as responsabilidades esmagadoras do Estado moderno, que a importância da formação sistemática de certos tipos de competências administrativas para o serviço público ressalta em toda a sua plenitude. (...). (Benedicto Silva, na instalação da Escola Brasileira de Administração Pública — EBAP, em 15 de abril de 1952; grifo nosso)

Essa passagem de um dos idealizadores da EBAP-FGV inaugura, academicamente, a "formação sistemática de certos tipos de competências administrativas para o serviço público" no Brasil, com a instituição do ensino superior de administração pública — em nível de graduação - no país.

Na ocasião, a formação de administradores públicos era reclamada ante a transição, desde os anos 1930, de um Estado de moldes liberais - com funções que se restringiam tão somente ao funcionamento do sistema político e atividades como a diplomacia, magistratura e segurança - para um Estado administrativo, que incrementou as velhas demandas e colocou novas exigências em torno do aparelho público-estatal, seja pela emergência de uma sociedade urbano-industrial, seja pelo ideário da modernização administrativa (e do desenvolvimentismo). 
Nos anos que se seguiram, é evidente que se sucederam rupturas, mudanças, adaptações e continuidades nas ideias/valores, organização pedagógico-curricular e vínculos com o setor público desse curso no país. Em linhas gerais, essa trajetória foi descrita e analisada pela investigação minuciosa de Fischer (1984), além da contribuição dos trabalhos — em ordem cronológica — de Bauzer (1965, 1966), Machado (1966), Wahrlich (1967), Guerreiro e colaboradores (1968), Vieira (1976), Johnson (1977), Sant'ana (1977), Cavalcanti (1981, 1984, 1991), Fischer (1993), Mezzomo Keinert (1994, 1996), Andrade (1995), Ckagnazaroff (1997), Gaetani (1999), Coelho (2006) e Nicolini (2007).

Contudo, exceto no artigo de Silva (1958), pouco se escreveu sobre a pré-história do ensino de graduação em administração pública no Brasil; isto é, seus antecedentes carecem de sistematização. Defronte desta lacuna, o objetivo deste artigo é passar em revista as origens desse ensino no país, com o propósito de compreender a evolução da ideia de instituí-lo na educação superior nacional (1854-1952).

A importância de trabalhos de tal natureza reside na contribuição para a construção de uma memória da área de conhecimento de administração no Brasil, em geral, e do seu ensino (e pesquisa), em particular, conforme sugere Curado (2001:1).

O estudo da história permite ao homem compreender e incorporar, num sistema coerente, tudo o que ele cria, faz e transforma, na produção e na explicação de sua existência. A história permite ao homem interrogar e refletir sobre sua existência, lhe fornecendo um "fio condutor". Na administração, apesar da importância da reflexão sobre a trajetória histórica do campo de conhecimento, existem poucos estudos históricos, principalmente na pesquisa da administração brasileira. (grifo nosso)

Ademais, no campo do saber de administração pública, a abordagem histórica, segundo Pacheco (2003:69), foi olvidada na última década. Pelas suas palavras, "os autores privilegiam temas da atualidade, o que talvez denote a vinculação estreita entre a área de pesquisa em administração pública e a agenda de governo, ainda que negada por vários de seus pesquisadores" (grifo nosso). Portanto, este artigo justifica-se pela escassez de estudos/pesquisas historiográficas no país, tanto na área de ensino de administração, como na área de administração pública, debruçando-se sobre a gênese do ensino de graduação em administração pública no Brasil.

Metodologicamente, o artigo se constrói pela revisão bibliográfica de obras que abordam direta e indiretamente o tema, incluindo a revisita de suas fontes de consulta; e análise documental de leis, portarias, resoluções e pareceres sobre o ensino de administração pública no Segundo Império, na República Velha e no Estado Novo, dentre outros documentos.

Em linhas gerais, pela revisão bibliográfica e análise documental — supramencionadas - levadas a cabo, observou-se que as referências em torno do ensino de graduação em administração pública (AP) no Brasil, que precedem seu estabelecimento nos anos 1950, se dividem em três momentos nítidos, conexos e sucessivos que se desdobram desde a apreciação das reformas educacionais no Império à concretização da Fundação Getulio Vargas (FGV) em 1944, que culminou na concepção da Escola Brasileira de Administração Pública (EBAP) no ano de 1952. O quadro 1 desvela tais momentos. 


\section{Quadro 1 \\ Momentos que antecederam (e originaram) o ensino de graduação em administração pública no Brasil (1854-1952)}

\begin{tabular}{|c|c|}
\hline 1ㅇ momento & \\
\hline \multicolumn{2}{|c|}{$\begin{array}{l}\text { No bojo das discussões sobre a ampliação do ensino comercial e a organização das faculdades de direito no país - na segunda } \\
\text { metade do século XIX -, se fez alusão, pela primeira vez, ao ensino superior de administração pública. Todavia, o entendimento } \\
\text { de que tal ensino se assemelhava ao do bacharelado em ciências jurídicas, seja pela jurisdicionalização das atividades simples } \\
\text { (e residuais) do Estado oligárquico, seja pela sujeição do campo do saber de administração pública ao direito administrativo, } \\
\text { perdurou até os anos 1930; assim, os intentos de um curso superior voltado - exclusivamente - para a administração (e } \\
\text { negócios) do Estado não avançaram. }\end{array}$} \\
\hline $2^{\circ}$ momento & $\begin{array}{l}\text { sições para a institucionalização do ensino superior de administração } \\
\text { ão no Brasil pós-1930 }\end{array}$ \\
\hline \multicolumn{2}{|c|}{$\begin{array}{l}\text { A organização de um Estado administrativo no país entre 1930-44 e, neste ínterim, a redefinição do focus do estudo de ad- } \\
\text { ministração pública para o conceito de que "governar é administrar" - sob a égide da scientific management - constituíram } \\
\text { fortes razões para a concepção (e implementação) da formação acadêmica em AP na ocasião. Efetivamente, o Dasp instituiu } \\
\text { a carreira de técnico de administração no aparelho do Estado e implantou o T\&D em administração pública no país. Contudo, } \\
\text { as proposições de se estruturar, academicamente, o ensino de AP não vingaram; conjectura-se que o questionamento se a } \\
\text { administração era arte ou ciência à época e as disputas das corporações de ofício pelo monopólio das funções administrativas } \\
\text { no Estado Novo foram alguns dos muitos obstáculos para a oficialização do ensino superior de ADM. }\end{array}$} \\
\hline 3ㅇ momento & \\
\hline \multicolumn{2}{|c|}{$\begin{array}{l}\text { É no encadeamento das ações da FGV entre } 1944 \text { e 1952, fundada (e conduzida) por técnicos do Dasp, que o ensino supe- } \\
\text { rior de administração pública institucionalizou-se no Brasil. Articulada num momento em que o sistema universitário nacional } \\
\text { deslocava-se da referência europeia para a tendência norte-americana, a FGV - com o apoio das Nações Unidas (ONU) e } \\
\text { com a cooperação de universidades dos Estados Unidos - instalaria, no Rio de Janeiro, a Escola Brasileira de Administração } \\
\text { Pública (EBAP) que, precursoramente, formaria bacharéis neste campo do saber (conciliando o embasamento teórico das } \\
\text { humanidades com um vertente funcional-instrumental de gerência pública). }\end{array}$} \\
\hline
\end{tabular}

Fonte: Elaboração dos autores.

A seguir, em seções, percorrer-se-á esse caminho, ora descrevendo, ora analisando cada um desses momentos.

\section{Das alusões no Império ao advento da administração científica no Brasil}

Silva, perscrutando os anais do parlamento e artigos de lei que se referem ao ensino superior no Segundo Reinado, mostra que as noções/ensaios sobre a instrução em administração pública são, aproximadamente, "contemporâneas da maioridade de Dom Pedro II" (1958:2). Eis excertos de discursos e relatórios da época que indiciam, respectivamente, as menções e iniciativas de uma formação acadêmica para o serviço público: 
[Deputado Silva Ferraz, discutindo o ensino comercial] (...) Creio necessária uma Escola de Administração. E será possível uni-la à de Comércio, de que trata esta lei? Se não é possível, que se introduza ao menos nesta escola uma cadeira de Direito Administrativo, e grande parte das matérias que nela se ensinam, entra no ensino da Ciência Administrativa. (...). Façamos este ensaio. (Anais do Parlamento Brasileiro, 1954, Tomo I, apud Silva, 1958:7)

[Ministro Liberato Barroso, aventando a dicotomização do curso de direito]. (...) Era geralmente reconhecida a necessidade de se separar as ciências propriamente jurídicas das ciências sociais, dividindo o curso em duas seções. Os indivíduos, que pretendem seguir a carreira da magistratura e advocacia, não precisam dos mesmos estudos que são necessários aos que abraçam a carreira administrativa e política. (Relatório do Império, 1865, apud Silva, 1958:9)

[Ministro Leôncio de Carvalho, autor de projeto de lei de reforma do ensino superior]. Parágrafo 8o do Art. 23 do decreto ํo 7.247, de 9 de abril de 1879 - "O grau de bacharel em ciências sociais habilita, independentemente de exame ou concurso, para os lugares de adidos de legação, bem como para os de praticantes e amanuenses das Secretarias de Estado e demais repartições públicas". (Relatório do Império, 1879, apud Silva, 1958:12)

Sob o escudo do enunciado de Silva Ferraz (1854), do esboço de Liberato Barroso (1865) e do projeto de Leôncio de Carvalho (1879), Rui Barbosa, em parecer sobre o ensino superior do país em 1882, amplia e aprofunda a concepção de um curso superior para formar egressos que viessem a exercer com competência as funções administrativas nas dependências do Império.

Inspirado naquelas noções que o antecederam e em seu conhecimento da máquina administrativa da Corte, o então deputado - relator da Comissão de Instrução Pública — encampa a ideia de um curso de ciências sociais, aventando o currículo inscrito no quadro 2:

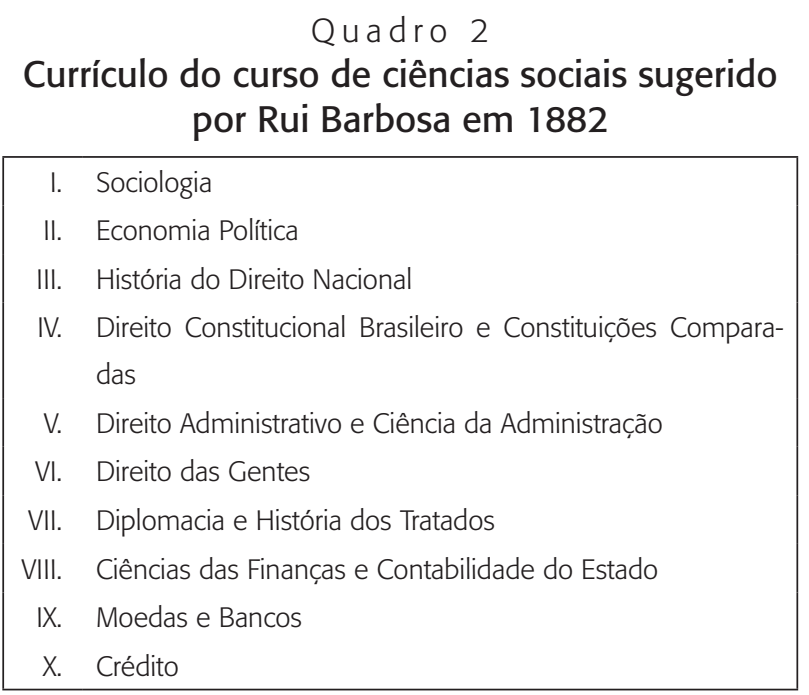

Fonte: Ministério da Educação e Saúde Pública (1942:222). 
Portanto, é no bojo das discussões nacionais sobre a ampliação do ensino comercial e a organização das faculdades de direito — no decorrer da segunda metade do século XIX — que se faz alusão, pela primeira vez no país, ao ensino superior de AP, proposto sob a nomenclatura de "curso de ciências sociais" e claramente delineado à luz do enfoque jurídico, circunscrevendo a administração do aparelho do Estado aos aspectos legais.

Segundo Muñoz Amato (1958:19), essa concepção legalista "que identifica[va] a administração pública com as regras jurídicas e reduz[ia] seu problema à elaboração de leis e regulamentos de aplicação geral - com todos os pormenores para seu cumprimento automático" —, coadunou, na América Latina, o estudo das ciências administrativas ao do direito administrativo.

Essa justaposição do estudo de AP e do pensamento do direito administrativo nas ex-colônias espanholas e no Brasil - entre o final do século XIX e início do século XX — advém dos estudiosos/tratadistas da época que, sob a influência da legislação romana oriunda da "metrópole", consideravam essas disciplinas como a investigação de "diferentes aspectos de um mesmo fenômeno". E em vista desta acepção de "fenômeno único", afirmavam que ambas "não podiam se ignorar mutuamente sob pena de não apreender em sua plenitude o seu objeto de estudo" (Wahrlich, 1979:35, tradução nossa).

Inclusive, diferenciar as duas disciplinas e caracterizar cada uma delas constituiu matéria de debate e problema de pesquisa nos primórdios da documentação do conhecimento em administração pública no Brasil. Por conta desse vínculo — isto é, dessa relativa sujeição — do campo do saber em administração pública à doutrina do direito, torna-se patente - conforme Mezzomo Keinert (1994) — que o focus da incipiente produção técnico-científica da área no país, entre 1900 e 1930, foi a ciência jurídica.

Da mesma maneira que o enfoque jurídico caracterizou o nascimento da corrente de pensamento em administração pública no Brasil, por consequência, também permeou as esparsas propostas de estabelecimento desse ensino naquele período; veja-se, por exemplo, o desígnio de Rui Barbosa. Não obstante, esses intentos não se manifestaram em experiência usual e institucionalizada até os anos 1930, cingindo-se a práticas indiretas, isoladas e, às vezes, não regulamentadas de algumas instituições de ensino de ministrar o estudo de AP.

Nas faculdades de direito - regulamentadas desde 1854 — o estudo de AP se fez presente, subordinadamente, em "minguados capítulos dos programas de direito administrativo". De acordo com Lordello Mello (1954:30), "tal prática acarretou uma grande distorção da teoria da administração pública [no país] no afã que tinham os professores de direito de pôr aquela teoria em conformidade com o sistema de relações legais".

No ensino secundário o estudo de AP se deu implicitamente na instrução profissional das "artes e ofícios" comerciais, da qual funcionários públicos e pretendentes a tal cargo se fizeram valer. Nesse magistério se tem notícia da Escola Prática de Comércio de São Paulo e da Academia do Comércio no Rio de Janeiro, datadas de 1902. Entretanto, ao invés da concepção legalista das faculdades de direito, nesse ensino prevalecia uma concepção mecanicista — de organizações e métodos $(\mathrm{O} \& \mathrm{M})$ - que equiparava a repartição pública à organização privada. É essa concepção mecanicista - com modificações e aperfeiçoamentos, evidentemente - que despontará no Brasil em meados dos anos 1930 por efeito do aporte das ideias da escola clássica da administração no país. 
Entrementes, nos Estados Unidos (EUA) e, secundariamente, na Europa Ocidental, essa "escola clássica" delineava a natureza e o escopo da administração pública sob os fundamentos da dicotomia entre política e administração de Woodrow Wilson, de 1887, do modelo burocrático weberiano, da organização do trabalho de Frederick Taylor, de 1911, e dos processos administrativos de Henri Fayol, de 1916, engendrando uma racionalidade administrativa no aparelho do Estado. A fundação do Bureau of Municipal Research, de Nova York, em 1906 - destinado a estudar os problemas de governo das cidades e treinar pessoal para a administração municipal —, e, posteriormente, a criação de schools of public affairs/administration em universidades norte-americanas nos anos 1920 são vestígios da penetração do paradigma da gerência científica no ensino e pesquisa de AP nesse país.

No Brasil, concomitantemente, o ensino superior de administração, seja para o setor público ou para gestão de empresas, não se afigurou. Na década de 1920, o advento do taylorismo/fayolismo no país teve eco apenas na formação acadêmica de engenharia, cujos cursos passaram a conter uma cadeira — ministrada no terceiro ano — intitulada "Organização e tráfego das indústrias, contabilidade pública e industrial e direito administrativo", decretada pela Reforma Rocha Vaz em 1925 (Silva, 1958).

Sintetizando, ainda que a formação de bacharéis para a administração pública tenha sido proposta em termos organizativo-pedagógicos desde o Segundo Reinado, o entendimento de que o ensino de administração pública se assemelhava ao do bacharelado em ciências jurídicas perdurou no país até o início dos anos 1930, concorrendo para o malogro dos planos de implantação de um curso superior voltado exclusivamente para a administração (e negócios) do Estado.

Com efeito, é no contexto político-institucional da Era Vargas - com a organização de um Estado administrativo que se contrapunha aos moldes do liberalismo econômico vigente na República Velha - que se assentam as condições e motivações para criação de cursos incumbidos de formar, em nível superior, uma burocracia especializada na gerência de órgãos/ departamentos públicos.

\section{Fortes razões e frágeis proposições para a institucionalização do ensino superior de administração pública em nível de graduação no Brasil pós-1930}

Indiscutivelmente, é na Segunda República - mormente no Estado Novo — que se lançam as bases para a edificação de um Estado administrativo no país. O "deslocamento do centro dinâmico da economia brasileira" para um sistema industrial, trazendo à tona o processo de urbanização, impeliu o Estado para investimentos na indústria de base, na infraestrutura de comunicações, transporte e energia e nas políticas sociais. Para se desincumbir desses encargos — residuais ou inexistentes anteriormente —, seguiram-se a criação de ministérios, autarquias e sociedades de economia mista, transformando as feições da administração pública para o fomento do desenvolvimento econômico-social.

No âmago desse desponte do capitalismo industrial no país e da consequente (re)estruturação e expansão estatal é que a ciência da administração começou a ganhar espaço, importância e status como atividade profissional e campo de ensino e pesquisa. Dentre as marcas 
desse início de valorização da racionalidade administrativa, destacam-se a criação do Instituto de Organização Racional do Trabalho (Idort) e do Departamento Administrativo do Serviço Público (Dasp), ambos introduzindo no Brasil os princípios de administração da escola clássica; o primeiro na organização industrial e o último na máquina governamental.

O Idort, fundado por intelectuais e empresários na cidade de São Paulo em 1931, é considerado a primeira instituição de treinamento em administração da América Latina. Reconhecido como de utilidade pública pelo governo federal em 1936, o Idort, sob o patrocínio da Federação das Indústrias de São Paulo, difundia o ideário/instrumental da administração científica para o empresariado do eixo São Paulo-Rio de Janeiro, servindo até mesmo como entidade de influência destes na política Varguista (Brandão, 1999).

O Dasp, por sua vez, criado em 1938 por meio do Decreto-Lei no 579 para ser o "braço administrativo" do Estado Novo, assumindo ares de superministério onde coexistiam as funções de departamento de administração - relacionadas a pessoal, material, orçamento e $\mathrm{O} \& \mathrm{M}$ - e órgão de assessoria da presidência. No que se refere ao ensino de administração pública, o Dasp, dentro de seus esforços na área de recursos humanos, introduziu essa temática disciplinar em caráter de T\&D no Brasil, sendo o principal locus de seu estudo, divulgação e instrução até o princípio dos anos 1950 (Fisher, 1984:48-54).

Enquanto núcleo de propagação das teorias de Taylor e Fayol em geral e das doutrinas de Willoughby e Gulick em particular, além de órgão da reforma administrativa entre 1938 e 1945, o Dasp redefiniu o focus do estudo de administração pública no país dentro do conceito de que "governar é administrar", suscitando que o enfoque jurídico não era a solução administrativa, senão uma de suas facetas. Segundo Mezzomo Keinert (1994), neste comenos o campo do saber em AP transmutar-se-ia em uma corrente de pensamento de orientação instrumental, mecanicista e prescritiva, ignorando a política e pondo em voga as noções de eficiência, neutralidade e aplicabilidade a qualquer contexto. As evidências para tal se encontram nos artigos da Revista do Serviço Público (RSP) publicada desde 1937, e a partir de 1938 sob a editoração do Dasp.

Esse contexto em que a administração pública projeta-se como ciência administrativa, do qual o Dasp é protagonista, terminou resultando em uma nova carreira no aparelho do Estado: técnico de administração. Embora o termo hoje nos remeta a uma qualificação de nível médio, na época referia-se aos experts em serviço público, que "aos predicados morais de decência, honradez e modéstia (...) deveriam aliar uma combinação de qualidades excepcionais: o comando das mais variadas técnicas e a posse de refinadas habilidades administrativas" (Silva, 1958:6, grifo nosso).

Consoante a máquina administrativa do Estado crescia e a grande empresa - integrada verticalmente - se instalava no país, constatava-se uma escassez de pessoal qualificado para ocupar os cargos de alta e média gerência na administração pública e na iniciativa privada. Essa carência de profissionais com conhecimentos especializados e domínio ferramental em administração refletia, de certo modo, uma lacuna do ensino superior nacional, até então centrado na formação de advogados, engenheiros e médicos. A respeito deste gap, ressalte-se que o Manifesto dos Pioneiros da Educação Nova, em 1932, incitava a criação de um curso superior tanto para a gestão de negócios quanto para a planificação econômica. 
Enfim, as transformações do Estado e o processo de industrialização em geral, e a criação do Idort e do Dasp sob a égide da escola clássica em particular, constituíam fortes razões para a inclusão da formação, em grau universitário, do "administrador profissional” no Brasil pós-1930. No entanto, essas fortes razões - que contribuíram para implantar o ensino de administração em nível de T\&D no país - não se equivaleram nas proposições para a institucionalização de um curso superior na área entre 1931 e meados dos anos 1940. (Veja-se, a seguir, o insucesso das reformas educacionais deste período no que tange a tal área do conhecimento.)

Desde o estabelecimento do Ministério da Educação e Saúde Pública em 1931 sucederam-se reformas da educação superior na Era Vargas, regulamentando o ensino superior, tanto público como privado. Retomando a tendência centralizadora do período monárquico — não em termos de monopólio da criação e manutenção das instituições de ensino, mas de controle burocrático pela normatização e supervisão de toda a estrutura acadêmica -, essas reformas decretariam uma legislação extremamente detalhista que, entre outros ordenamentos, dispunha sobre questões como currículos e programas, contratação de professores, duração dos cursos, regime disciplinar, cobranças de taxas e pagamentos de mensalidade (Durham, 2005). Esse cunho formal-legal já se fez notar na Reforma Geral do Ensino, de 1931, de autoria do ministro Francisco Campos, que, ao organizar o ensino comercial do país, prescrevia um curso superior de administração e finanças, intentando um magistério misto de administração pública e de empresas com a grade curricular apresentada no quadro 3.

\section{Quadro 3}

\section{Currículo do curso superior de administração} e finanças criado em 1931

\begin{tabular}{|rl|}
\hline I. & Matemática Financeira \\
III. & Geografia Econômica \\
IV. & Finanças e Economia Bancária \\
V. & História Econômica da América e Fontes da Riqueza Nacional \\
VI. & Direito Constitucional e Civil \\
VII. & Direito Internacional Comercial \\
VIII. & Direito Administrativo \\
IX. & Direito Industrial e Operário \\
X. & Direito Público Internacional \\
XI. & Política Comercial e Regime Aduaneiro Comparado \\
XII. & Legislação Consular \\
XIII. & Ciência da Administração \\
XIV. & Contabilidade das Grandes Administrações \\
XV. & Contabilidade Pública \\
XVI. & Psicologia, Lógica e Ética \\
XVII. & Sociologia \\
\hline
\end{tabular}

Fonte: Coleção das Leis do Brasil. Atos do Governo Provisório (1931: v. II, 459). 
Contudo, a alta incidência de disciplinas da ciência jurídica não despertava nenhum interesse aos que almejavam as carreiras administrativas, porquanto a tradição do direito administrativo ibérico sobrepunha-se à nascente (e convidativa) escola da administração científica norte-americana. Além disso, no entender de Silva (1958:20):

O curso superior de administração e finanças apresentava algumas características estranhas e pilhéricas. Embora chamado curso superior na lei, não era reconhecido como tal pelo Ministério da Educação e Saúde Pública. Era de administração e finanças, mas o diploma conferido aos concluintes era de bacharel em ciências econômicas. Também, exigia dos candidatos, como requisito indispensável, a posse do diploma de perito-contador ou de atuário.

A bem dizer, parecia tratar-se de um artifício legal para conferir diploma de economia aos contadores (e atuários) de nível secundário, via um pretenso currículo de administração e finanças sob a tutela do direito. Ante essa distorção, o referido curso não encontrou lugar propício ao seu desenvolvimento e as estatísticas revelam que a tentativa foi totalmente frustrada (Moitinho, 1950).

Nos tempos de Gustavo Capanema à frente da pasta da educação (1934-45), em meio a disputas, debates e pressões em torno da criação de uma Faculdade de Ciências Políticas e Econômicas, as discussões sobre o ensino de administração pública são retomadas. Desejoso de corrigir as incoerências do curso superior de administração e finanças, o senador Waldemar Falcão apresentou ao Congresso, em 1935, um projeto de lei que projetava uma escola para o ensino superior de economia, política, administração e finanças, orientando-se, igualmente, pela preocupação político-administrativa e pela finalidade econômico-diplomática. O projeto foi parcialmente acolhido pelo Ministério da Educação e Saúde Pública, que em substitutivo propôs um currículo unificado de três anos e uma opção entre ciências políticas e ciências econômicas no quarto (e último) ano. Pela exposição de Schwartzman, Bomeny e Costa (2000:37), o atino do ministro Capanema era que os estudos de ciência política formassem técnicos para os public affairs e que o ensino de economia, além de seu papel tradicional, compartilhasse a função de preparar especialistas para a administração das corporações privadas. Valdemar Falcão discordaria, alvitrando que "a preocupação da política é ligar-se, evidentemente, à economia, e que a economia liberal padecia justamente do defeito de isolar os fenômenos econômicos dos fenômenos políticos" (Schwartzman, Bomeny e Costa, 2000:37). Ademais, no Senado o projeto de Waldemar Falcão foi substituído por outro subscrito pela Comissão de Constituição e Justiça, sendo aprovado pelo plenário em 1936. O substitutivo previa a abertura de quatro cursos, quais sejam: atuária, contabilidade, economia e administração pública. Respeitante ao diploma de bacharel em AP, o art. 16 concedia aos seus detentores as prerrogativas em sequência:

a) preferência, em relação aos demais candidatos, para provimento de cargos iniciais da administração pública, sempre que não se tratar de função técnica relativa a outra especialização; b) preferência, em igualdade de condições, para efeito de promoção nas repartições públicas, sempre que não se tratar de função técnica relativa a outra especialização; e 
c) preferência, a partir de cinco anos após o funcionamento da Faculdade, para o provimento nos cargos de coletor, estatístico, escrivão, guarda-mor, intendente, tesoureiro, almoxarife, arquivista e oficial administrativo dos serviços públicos. (apud Silva, 1958:23)

Embora as proposições - supramencionadas - definissem com clareza as fronteiras do conhecimento da administração pública e de suas aplicações laborais, distinguindo-a do ensino de direito, economia e contabilidade, as mesmas não produziram efeito concreto. O substitutivo do projeto do senador Waldemar Falcão pereceu na Câmara dos Deputados diante da supressão do Poder Legislativo em 1937. A Faculdade Nacional de Política e Economia — tal como idealizada pelo ministro Gustavo Capanema - chegou a ser criada oficialmente (Lei no 452, de 5 de julho de 1937), mas não fora implantada sequer na Universidade do Brasil, pertencente ao governo federal.

No ensino superior de administração, o resultado desses intentos confinados a retórica e/ou projetos de lei foi a subsistência do desprestigiado curso superior de administração e finanças até 1945, o qual era ofertado em alguns estabelecimentos privados que não passavam de extensões das escolas de comércio, ainda que tivessem, muitas vezes, o nome de "faculdade". Decerto, as deformidades curriculares do curso e seu status não universitário corroborariam para o difícil reconhecimento social da formação acadêmica em administração naquele momento.

Nestas circunstâncias, alguns empreendimentos autônomos com planos inovadores foram postos em prática. No ensino de administração de empresas, salienta-se a fundação da Escola Superior de Administração de Negócios (Esan) no município de São Paulo em 1941, inspirada no curso da Graduate School of Business Administration, da Universidade de Harvard. No ensino de administração pública, por seu turno, o Dasp criou programas de capacitação na área que ficaram conhecidos como "cursos do Dasp". Os principais conteúdos programáticos eram derivados dos ensinamentos da administração científica e complementados pelas normas constitucionais e do direito administrativo. Segundo Gaetani (1999:100), “[esses] programas, em muitos casos, eram articulados com a sistemática de concursos, de modo que muitos cursos revestiam-se de caráter preparatório para as seleções, e outros, de introdutório ao serviço público, no âmbito do período de estágio probatório".

Nada obstante, o curso da Esan e os treinamentos do Dasp não chegaram a lograr condição de formação acadêmica; afora a desvirtuada regulamentação do curso superior de administração e finanças, conjectura-se, dentre outras suposições, os seguintes obstáculos para a institucionalização do ensino de administração no Brasil entre os anos 1930 e o preâmbulo dos anos 1950:

v Entre os estudiosos (e críticos) da área do conhecimento de administração, repercutia ainda a velha noção de que as técnicas administrativas não podiam ser transmitidas pelo ensino formal e treinamentos específicos, já que - na interpretação destes - dependiam de qualidades inatas ou de longos anos de experiência. Nesta interpretação, a utilidade de se estudar gestão era questionada pelo juízo de que a competência do dirigente — quer pú- 
blico ou privado - devia-se mais a "formação do espírito" e aptidão do que a tecnicidade e instrução;

• Outrossim, levantava-se a questão se a administração era arte ou ciência. Essa interrogação acabou dificultando a delimitação dos contornos do campo do saber administrativo, confundindo-o com o direito administrativo e, posteriormente, com as ciências econômicas. Assim, o ensino de administração restringia-se a "lições" nos estudos de direito e economia ou, na melhor das hipóteses, se servia de cadeiras optativas nestas faculdades;

V A concepção de uma base comum entre administração e ciências jurídicas e, analogamente, entre administração e ciências econômicas tardou a emancipação de tal ensino e, por sua vez, a regulamentação da profissão. Indubitavelmente, a competição na época entre advogados, economistas e administradores pelo monopólio das funções administrativas — típica das corporações de ofício retratadas pela sociologia das profissões - consistiu num grande entrave para o processo de autonomia intelectual e legitimação acadêmica da ciência administrativa; e

v A influência europeia sobre o movimento de organização do sistema universitário brasileiro naquele período perfaz uma educação superior - no que se refere ao ensino das ciências sociais - clássica, literária e humanística, diferente do ímpeto utilitarista, empírico e pragmático que o ensino de administração urgia. Neste contexto, os estudos de gestão não encontraram terreno fértil nas instituições de ensino recém-criadas por causa da ausência e/ou preconceito da prática do extension work - essencial para o autodesenvolvimento disciplinar da área na proporção que gerava um fluxo recíproco de suporte intelectual entre docentes e organizações engajadas na aplicação do conhecimento.

Todavia, essa relutância não se verificou somente no Brasil. Conforme Keinert (1986), na Europa Ocidental, até a Segunda Guerra Mundial, o ensino de administração caracterizava-se pela concentração dos estudos em torno de uma disciplina em estabelecimentos como as faculdades de ciências econômicas aplicadas da Alemanha, as écoles de commerce francesas e os technical colleges da Inglaterra. No tocante a instrução preferencialmente em administração pública, atraía a atenção a iniciativa do governo francês de fundar, em 1945, a École Nationale d'Administration (ENA), destinada a preparar uma elite tecnoburocrática — líderes políticos, altos burocratas e empresários - capaz de contribuir decisivamente para o desenvolvimento do país.

Nos EUA, por outro lado, a formação acadêmica de administradores encontrava-se em franca proliferação. O ensino de administração pública, especificamente, aguçava-se mediante o Progressive Reform Movement que, sob o ideário da dicotomia política-administração, apregoava que o "melhor remédio" contra o clientelismo era o estímulo à profissionalização da administração pública. Neste ensejo, a escolarização e capacitação em administração pública era o antídoto contra os custos do amadorismo em governar. George Graham, no livro Education for public administration, de 1941, mostra que, no primeiro quarto do século XX, ao passo que o treinamento para o serviço público crescia nos departamentos de ciência política 
e nas escolas de management norte-americanas e se formulavam doutrinas acerca dos processos administrativos no governo, aumentavam as recomendações para a criação de programas acadêmicos e a concessão de graus específicos em AP. Dispunha-se a administração pública a reclamar uma vida universitária própria naquele país. Pugnava por independência e consideração como disciplina e profissão distintas; e foi nesse panorama que se fundou, em 1939, a American Society for Public Administration (Aspa), emancipando-se da American Political Science Association (Apsa), datada de 1903.

Esse sentido e ânimo ianque à volta do conceito de administração pública como um campo específico de estudo acadêmico aflorariam, ulteriormente, no Brasil a começar da "criação de uma entidade que se propunha ao estudo e a divulgação da organização racional do trabalho e ao preparo de pessoal qualificado para administração pública e privada": a Fundação Getulio Vargas (FGV).

Resumindo: até então, o cenário de alto teor reformista da Era Vargas - nas rédeas centralizadoras do Dasp - fez o focus da administração pública desprender-se do direito administrativo, propagando o ideário desse campo do saber enquanto ciência administrativa aplicada às atividades-meio do governo (O\&M, orçamento, pessoal e material), tal como prognosticavam os expoentes da escola clássica. Efetivamente, apesar de o ramo profissional emergir com a reforma administrativa e a capacitação de pessoal evidenciar-se com os "cursos do Dasp", as tentativas de se estruturar o ensino de AP em uma formação acadêmica não vingaram.

\section{Das origens da FGV à instalação da EBAP: contexto, preparativos e efeitos}

O ideal de um ensino sistemático de administração, nos mais variados níveis e setores de aplicação, independente das universidades brasileiras, remonta às deliberações entre os dirigentes do Dasp, a partir de 1943, para a abertura de um centro de estudo com a finalidade específica de fornecer tal instrução. Nas palavras de Luiz Simões Lopes — presidente do Dasp desde sua criação até a queda do Estado Novo - “(...) o Brasil precisava melhorar a sua administração pública. Esse era o meu sonho, e só havia uma maneira de realizá-lo: criando escolas de administração" (apud D’Araujo, 1999:13). Essa convicção em torno da formação de quadros para a modernização administrativa do Estado aliada à evidência do enfraquecimento do regime de Vargas - que calharia no esvaziamento do Dasp e, por conseguinte, na interrupção dos seus esforços de racionalizar a administração pública — originou a FGV.

Simultâneo à articulação da FGV no governo federal, o Sindicato dos Economistas do Estado de São Paulo (Sindecon) dirige carta — em julho de 1943 — ao ministro Capanema suscitando a ideia de

elevar ao grau universitário um curso único, em que se enquadrem as especializações de economia, administração e finanças. (...) Naturalmente, dado o interesse evidente pelas especializações nos diversos ramos de atividades públicas e privadas, poderiam ser criadas cadeiras optati- 
vas dentro do mesmo curso, cuja conclusão daria um grau único em economia e administração. (apud Schwartzman, Bomeny e Costa, 2000:238)

Conquanto a proposta do Sindecon fosse de absorver os estudos de administração geral pelo ensino de ciências econômicas, o Ministério da Educação e Saúde Pública submete à sanção presidencial um projeto de criação do curso de economia que excluía a administração, orientando-se, dentre outros, por intelectuais como Eugênio Gudin e Otávio Gouveia de Bulhões. Assim, o curso de economia abdicaria de sua "natureza genérica" e se especializaria nos altos estudos econômicos.

O resultado é o Decreto no 7.988 , de 22 de setembro de 1945, que transforma a antiga Faculdade Nacional de Política e Economia, criada em 1937 no "papel”, na Faculdade Nacional de Ciências Econômicas, extinguindo o inviável curso superior de administração e finanças que subsistia desde 1931 e criando os de ciências econômicas e ciências contábeis, este incluindo a atuária. Consolidando as categorias profissionais de economista e contabilista, o referido decreto "deixou inteiramente à margem, porém, o problema da formação específica de homens e mulheres para o exercício de cargos no serviço público, especialmente nos órgãos de estado-maior civil e nas repartições incumbidas de atividades administrativas" (Silva, 1958:24).

Ainda que as parcas referências bibliográficas sobre o ensino e a profissão de administração no Brasil não inter-relacionem os fatos, é de se estranhar a coincidência entre a constituição da FGV e a reforma educacional de Capanema que discernira o ensino de economia do estudo de administração, extirpando este e emancipando aquele. Todavia, fortuito ou não, renunciaremos a essa questão neste artigo.

A regulamentação da Faculdade Nacional de Ciências Econômicas, que estabelecia como "escola-padrão" a Universidade do Brasil, repercutiria na Universidade de São Paulo (USP) em 1946, resultando na criação da Faculdade de Ciências Econômicas e Administrativas (FCEA). Embora o vocábulo "administrativas" conste na denominação da FCEA, o bacharelado em administração instalar-se-ia apenas em 1964. "Sendo a USP um estabelecimento de ensino superior oficial, preferiu-se não se implantar na FCEA cursos que graduassem bacharéis para o exercício de uma profissão ainda não regulamentada por lei" (Toledo e Trevisan, 1984:71). Sem embargo, as graduações em ciências econômicas e ciências contábeis, instituídas desde a fundação da FCEA, incluíam disciplinas de ciência administrativa oferecidas pelo Instituto de Administração (IA). Sob a responsabilidade do IA, também, desenvolviam-se pesquisas, assessorias e treinamentos em gestão, enfatizando-se, até meados dos anos 1960, a administração pública. Tal como no governo federal, a reforma administrativa no estado de São Paulo propulsaria o ensino não formal (preparação, aperfeiçoamento e desenvolvimento) de AP, ministrado pelo IA nesta unidade da federação.

Enquanto o ensino superior de economia revestia-se de status universitário com sua oficialização e decorrente implantação nas duas mais importantes instituições acadêmicas brasileiras na ocasião - a USP e a Universidade do Brasil —, o ensino de administração mantinha-se como área de "estudo complementar" nesses cursos e como política/estratégia 
de formação de pessoal no âmbito das empresas privadas e do setor público. Embora a figura do assessor econômico ganhe relevo no pós-Bretton Woods com a ascensão da ideologia desenvolvimentista e a "atitude" de planificação no país, justificando o curso de economia, era também inegável a importância do técnico de administração para racionalizar os grandes aparelhos administrativos da indústria e do governo. Sem que uma lei instituísse o ensino superior de administração, de acordo com Martins (1989:665), era recorrente, nos documentos/pronunciamentos à época das origens da FGV e da criação da FCEA-USP,

(...) uma crítica à formação eminentemente humanista dos atores que se ocupavam dos negócios privados e públicos do país, (...) [evocando a necessidade de se investir] enfaticamente contra os autodidatas - que executavam planos com ares de sensatez, mas que em função de seu amadorismo estavam sempre destinados ao fracasso - , pela formação de um novo tipo de intelectual (...), o administrador profissional.

A impossibilidade dessa clivagem entre gestores praticantes e administradores profissionais pela, até então, irreconhecibilidade do ensino superior de administração pelos preceitos legais e autoridades educacionais do país, a despeito do empecilho de se instituir tal curso na FCEA-USP, não obstruiu os preparativos da FGV para encabeçar, autonomamente, a graduação nessa área do conhecimento. Alheia às normas (e ao modelo) da educação superior brasileira, a FGV, desde 1948, empenhou-se na criação de uma escola destinada à formação de jovens administradores e à difusão da teoria da administração no país. Projeto de Benedicto Silva - ex-técnico de administração do Dasp e funcionário do Brasil na ONU — no ano de 1949, a ideia materializar-se-ia no Instituto Brasileiro de Administração (Ibra) em 1951 e, nas dependências deste, surgiria a EBAP em 1952.

Entre os objetivos explícitos da EBAP, no ato de sua inauguração, encontrava-se o de "descobrir e lapidar talentos administrativos, (...) conferindo títulos que não tivessem apenas valor acadêmico, mas, principalmente, um conteúdo pragmático, valendo como garantia da prática diária, de aplicações concretas aos problemas da vida administrativa" (apud Costa, 1986:52). Quanto aos objetivos subjacentes, nota-se sua interpenetração com os motivos que originaram a FGV, cujo ideário deriva do Dasp. Ou seja, o papel da EBAP era, intrinsecamente, o de prosseguir, noutro nível, aquilo que os "cursos do Dasp" vinham propalando desde 1941: a tecnologia administrativa voltada à reforma e/ou modernização da organização público-estatal.

Conforme Moura Castro (1981), nesses anos de estreia do ensino de administração no Brasil - pela via da AP e pelas mãos da EBAP — , os EUA já formavam cerca de 50 mil bacharéis, 4 mil mestres e 100 doutores por ano nessa área do conhecimento. A respeito do bacharelado em public administration, Lordello Mello (1954) observara que, concernente aos objetivos que tinham em vista, os programas das universidades norte-americanas se classificavam em quatro tipos. Primeiramente, havia os cursos que buscavam preparar o aluno para o ingresso no serviço público, mas dando-lhe uma educação de natureza geral ao invés de um magistério especializado. Neste grupo estavam os programas oferecidos pelas universidades de Harvard, Cincinnati, Syracusa e Minnesota. Em segundo lugar, havia as instituições que 
se preocupavam mais com o preparo de alunos que já pertenciam à administração pública e cujos cursos procuravam atender às necessidades das agências governamentais situadas na região, tal como uma escola de governo. O exemplo cabal deste enfoque, segundo o autor, era o programa da Universidade de Wayne. Num terceiro tipo encontravam-se aquelas faculdades que mantinham certo equilíbrio entre as duas orientações anteriores, mesclando formação eclética e instrução profissional. Esse era o caso das universidades da Califórnia do Sul, Michigan, Nova York e Princeton. Por último, figurava a maioria das universidades cujo ensino de AP se limitava a algumas disciplinas nos departamentos de ciência política, tal como ocorria nas universidades de Colúmbia, Chicago, Yale e Wisconsin.

Essa heterogeneidade de experiências educacionais em AP ainda na década de 1950, associada à feição prática-experimental de alguns cursos/programas universitários que prestavam assessoria e capacitação no aparato governamental, logo permitiria à vanguarda dos professores pesquisadores norte-americanos questionar a abordagem estreita, insular e, em certa medida, artificial que dicotomizava política e administração, enclausurando a administração pública nas formulações/técnicas da escola clássica. Gradativamente, tornar-se-ia "visível que as diretrizes administrativas eram fortemente afetadas pelo ambiente político do serviço público, e que a ideia de uma atribuição separada, objetiva e científica para a administração pública era mais mito do que realidade" (Bailey, 1968:216).

Distante dessas indagações - seja pela inexperiência do Brasil nesse ensino em nível superior, seja pela inexistência de uma comunidade científica nesse campo do saber no país -, e diante do relativo déficit de racionalização/eficiência na máquina administrativa do Estado nacional, a FGV, sob a ascendência dos instrutores do Dasp e os ditames da assistência técnica norte-americana, realçou a gerência pública na formação acadêmica ebapiana, evidenciada pelo currículo que amparou o curso de graduação em administração pública em sua implementação, à mostra no quadro 4.

Pelo exposto, o Curso de Formação que prenunciou a EBAP conciliava o embasamento teórico das humanidades (ciência política, sociologia, antropologia, economia, história e filosofia) com uma vertente funcional-instrumental de gerência pública (finanças públicas, relações públicas, administração municipal, administração de pessoal). Neste caso, ressalta-se que a ausência de subáreas da administração como Organizações e Métodos (O\&M) e o fato de Administração de Pessoal ser eletiva decorriam, parcialmente, da falta de professores e da escassez de literatura no país naquela ocasião. Ao passo que a EBAP contratava professores norte-americanos (e brasileiros recém-chegados de treinamento intensivo em universidades dos EUA) e coletava fontes de consulta suscetíveis de serem adotadas como material de estudo, essas disciplinas foram acrescidas e/ou converteram-se em cátedra obrigatória. Além disso, o fato de se ministrarem os conteúdos de gestão tão somente no terceiro ano, segundo Paulo Motta (ex-aluno - 1961-64 - e professor da EBAP), explicava-se pela inexistência no Brasil de um currículo (mínimo) de administração; "[assim], optou-se por oferecer aos graduandos uma extensa e densa introdução às ciências sociais, [evitando que se cogitasse] que a formação acadêmica em administração era [algo] pequenez, burocrático" (Entrevista realizada pelos autores). 
Quadro 4

Currículo do Curso Formação em Administração Pública da EBAP entre 1952-54*

\begin{tabular}{|c|c|c|}
\hline $\begin{array}{l}\text { Psicologia } \\
\text { Sociologia } \\
\text { Economia } \\
\text { Estatística } \\
\text { Disciplina Eletiva }\end{array}$ & $1^{\circ}$ Ano & $\begin{array}{l}\text { Psicologia II } \\
\text { Sociologia II } \\
\text { Economia II } \\
\text { Antropologia Cultural } \\
\text { Disciplina Eletiva }\end{array}$ \\
\hline $\begin{array}{l}\text { Ciência Política } \\
\text { História Contemporânea } \\
\text { Problemas da Vida Rural } \\
\text { Direito Público } \\
\text { Disciplina Eletiva }\end{array}$ & $2^{\circ}$ Ano & $\begin{array}{l}\text { Ciência Política II } \\
\text { Cultura Brasileira Contemporânea } \\
\text { Problemas da Vida Urbana } \\
\text { Inst. Governamentais Comparadas } \\
\text { Disciplina Eletiva }\end{array}$ \\
\hline $\begin{array}{l}\qquad 1 \text { o Semestre } \\
\text { Direito Administrativo } \\
\text { Filosofia Política } \\
\text { Finanças Públicas } \\
\text { Relações Públicas } \\
\text { Elementos de Administração Pública }\end{array}$ & $3^{\circ}$ Ano & $\begin{array}{l}\qquad 2^{\circ} \text { Semestre } \\
\text { Direito Administrativo II } \\
\text { Elementos de Administração Pública II } \\
\text { Governo e Administração no Brasil } \\
\text { Administração Municipal } \\
\text { Métodos de Pesquisa em Adm. Pública }\end{array}$ \\
\hline \multicolumn{3}{|c|}{ Disciplinas eletivas } \\
\hline $\begin{array}{l}\text { História da Filosofia } \\
\text { Geografia Econômica } \\
\text { Língua Inglesa } \\
\text { Língua Francesa }\end{array}$ & & $\begin{array}{l}\text { Contabilidade Geral } \\
\text { Testes e Medidas } \\
\text { Compras e Suprimentos } \\
\text { Administração de Pessoal }\end{array}$ \\
\hline
\end{tabular}

Fonte: FGV/EBAP (1954).

* As primeiras turmas formaram-se em três anos. O acréscimo de mais um período escolar no curso foi feito em 1955, passando, então, a ser ministrado em quatro anos. Além disso, até 1964 a graduação da EBAP denominava-se "Curso de Formação" em razão da falta de regulamentação do ensino de administração no país.

Destarte, apartado da arena do direito público e, ainda, sem a índole da embrionária "administração para o desenvolvimento", ganhava identidade o ensino superior de administração pública no Brasil, incorporando as cadeiras básicas das ciências sociais e as aplicações das ciências administrativas - notadamente do scientific management - no setor público. Oportunamente, o monólogo da EBAP que caracterizou o limiar dos anos 1950 transformar-se-ia em diálogo nacional em meados dos anos 1960.

Assim, nascido sob o signo da administração científica (aplicada ao setor público) na EBAP em 1952, o bacharelado em AP reproduziu-se em IES pelo país, preponderantemente 
nas universidades federais, com a ascendência da administração para o desenvolvimento, à medida que aos processos administrativos do governo agregavam-se as funções econômico-sociais do Estado. Na metade dos anos 1960, dos 31 cursos de administração no país, dois terços eram de administração pública ou enfatizavam esse campo do saber. Neste contexto, a profissão seria reconhecida, após anos de embate e contestações, em 1965 (Lei no 4.769), e o ensino seria regulamentado pelo Parecer no 307 e a Resolução s/n do CFE, em 1966.

\section{5. À guisa de conclusão}

Este artigo, um retrospecto - ora descritivo, ora analítico — dos antecedentes (e origens) do ensino de graduação em administração pública no Brasil, procurou revistar a pré-história (na acepção de momentos) da formação acadêmica em administração pública no país, contribuindo para a sistematização de sua memória.

Considerado embasamento histórico, os relatos/constatações deste artigo são, per se, um constructo para se refletir, retrospectivamente, sobre o ensino de graduação em administração pública no país. Indubitavelmente, uma investigação (e compreensão) desse objeto de estudo no presente sem as suas referências do passado resultaria num trabalho (e entendimento) falho e/ou incompleto.

Situando (e examinando) a evolução da ideia de instituir a formação acadêmica em administração pública no Brasil como variável dependente das vicissitudes do Estado nacional e das conformações do campo do saber em administração pública, o trabalho desvelou os três momentos nítidos, conexos e sucessivos entre 1854 e 1952 que gestaram tal curso superior, explicitando os projetos políticos, as concepções de curso, os designs de currículos e as disputas (e os debates) sociais em torno da institucionalização do ensino (e da profissão).

No primeiro momento, de 1854 a 1930, o Estado já demandava pessoas com estudos administrativos para vários níveis das funções do Império e da República Velha. O surgimento dos estudos de AP se deu de forma incipiente no bojo dos cursos de direito, que haviam sido regulamentados desde a segunda metade do século XIX. Assim, o enfoque jurídico caracteriza de forma marcante a influência do direito sobre a administração pública: nada menos que metade da matriz curricular do currículo de ciências sociais proposto por Rui Barbosa em 1882 foi pinçada daquele curso.

Concomitantemente, acontece a organização das faculdades de direito, onde o estudo de AP se faz presente, ainda que restrito aos estudos do direito administrativo, o que caracteriza uma influência mútua, ainda que fortemente pendente para o direito. Assim, a ciência administrativa é subsidiariamente ensinada a reboque do direito administrativo, na concepção legalista que acreditava que a AP se reduzia à elaboração de leis e regulamentos para aplicação automática. Esta situação vai perdurar até os anos 1930.

A importância crescente dos estudos de AP que pudessem embasar a construção de um Estado administrativo marca o segundo momento, de 1930 a 1944 . O deslocamento do centro dinâmico da economia do Estado para a indústria já demandava a formação de administrado- 
res, tanto para as empresas nascentes quanto para um Estado que precisa rever seu papel. O esforço de organizar o estudo de AP no Brasil recebe forte apoio com o advento das ideias de Taylor e Fayol, do início do século XX. Essas ideias começam primeiro a influenciar as faculdades de engenharia, e mais tarde assaltam a área de administração, contribuindo para construir um ideário científico para a disciplina.

Neste contexto, instituições com o Idort e o Dasp desempenham um papel fundamental para a organização dos estudos em administração. O Dasp foi peça fundamental neste cenário, introduzindo os princípios da administração clássica nos cursos de T\&D que promovia e disseminando a ideia de que governar era administrar. Logo ele se constituiria como braço administrativo para governar o Brasil, concentrando as funções de pessoal, material, orçamento e O\&M, assessorando diretamente a Presidência da República. Por sua atuação também foi instituída uma nova carreira de Estado, o técnico em administração, que à época dominaria as mais apuradas técnicas de gestão e se constituiria numa força de elite para o comando da máquina de governo.

Assim, a convergência do conhecimento científico em gerência, de órgão demandante de pessoal qualificado e a criação de uma carreira específica para tal começam a desenhar o cenário para a formação universitária em administração pública. Embora as discussões sobre um curso superior para a AP avançassem no Congresso e no governo, não foi possível evoluir para uma proposição curricular consistente além do Curso Superior de Administração e Finanças, criado em 1930. Neste curso já se podia distinguir que a AP ganhara ao menos uma disciplina, apesar da influência das ciências jurídicas, que dividiam importância, naquele momento, com as ciências econômicas que dão forma ao curso.

Situado entre 1944 e 1952, o terceiro momento é distinguido pela emancipação dos estudos e ensino em administração pública. É, então, o próprio Dasp a responder à necessidade de se criar escolas de administração. Apesar da irreconhecibilidade da formação superior em administração, que se encontrava em processo de clivagem da formação correspondente em economia, a recém-criada Fundação Getulio Vargas empenhou-se na criação de escola para formar jovens administradores.

Ainda que a regulamentação profissional demore mais de uma década, a FGV vai cumprir o legado gestado no Dasp de disseminação da teoria administrativa e formação de jovens talentos para o serviço público, com forte contorno pragmático. A identidade do curso, forjada na lógica de universidades norte-americanas como Southern California e Michigan State, mescla formação em ciências sociais e instrução profissional em proporções semelhantes, como prova o currículo da EBAP.

Assim, o primeiro currículo em administração pública do Brasil criaria a qualificação - o conjunto de saberes necessários ao exercício profissional - necessária ao jovem administrador. É esse currículo que começou a forjar a identidade do administrador público e que vai servir de modelo para a expansão desta formação no país até meados dos anos 1960, quando a profissão é regulamentada (1965) e desenha-se o primeiro currículo mínimo da área (1966). 


\section{Referências}

ANDRADE, Rui O. B. O ensino de administração: história e diagnóstico. Dissertação (mestrado) Escola Brasileira de Administração Pública, Fundação Getulio Vargas, Rio de Janeiro, 1995.

BAILEY, Stephen K. O progresso da administração pública como disciplina nas universidades norteamericanas. Documento apresentado na Conferência Aspa/Ladac-FGV, realizada no Rio de Janeiro, em novembro de 1967. Rev. Adm. Pública, v. 2, n. 4, p. 211-222, jul./dez. 1968.

BAUZER, Riva. Formação para a administração pública: seleção de candidatos ao curso superior de graduação da EBAP. Cadernos de Administração Pública - EBAP, n. 56, p. 1-28, 1965.

BAUZER, Riva. Formação para a administração pública: um estudo sobre escolha ocupacional e preparação profissional. Cadernos de Administração Pública - EBAP, n. 77, p. 1-144, 1970.

BAUZER, Riva. Formação para a administração pública: vestibulandos, ebapianos e bacharéis em administração pública: aspectos da formação universitária para o exercício das mais altas funções de administração pública do Brasil. Cadernos de Administração Pública - EBAP, n. 63, p. 1-169, 1966.

BRANDÃO, Marisa. Da arte do ofício à ciência da indústria: a conformação do capitalismo industrial no Brasil vista através da educação profissional. Boletim Técnico do Senac, v. 25, n. 3, p. 16-29, set./dez. 1999.

CALDWELL, Lynton K. Public administration and the universities: a half-century of development. Public Administration Review, v. 25, n. 1, p. 52-60, mar./abr. 1965.

CARVALHO, José S. EBAP: as experiment in institution building. Tese (doutorado) - University of Southern California, Los Angeles, 1967.

CAVALCANTI, Bianor S. A gestão pública como componente do desenvolvimento curricular das escolas de administração. Rev. Adm. Pública, v. 18, n. 4, p. 235-240, out./dez. 1984.

CAVALCANTI, Bianor S. A gestão pública integrada: implicações para a formulação de teorias, modernização administrativa e ensino de administração pública. Rev. Adm. Pública, v. 25, n. 3, p. 173-184, jul./set. 1991.

CAVALCANTI, Bianor S. Formação do administrador público: alternativas em debates. Rev. Adm. Pública, v. 15, n. 3, p. 31-53, jul./set. 1981.

CKAGNAZAROFF, Ivan B. Ensino de administração pública no Brasil. Cadernos de Textos, Fundação João Pinheiro, n. 2, 1997.

COELHO, Fernando S. Educação superior, formação de administradores e setor público: um estudo sobre o ensino de administração pública — em nível de graduação — no Brasil. Tese (doutorado) — Escola de Administração de Empresas de São Paulo, Fundação Getulio Vargas, São Paulo, 2006.

COELHO, Fernando S.; NICOLINI, Alexandre M. Como tudo começou? Apontamentos históricos sobre a implantação do ensino de graduação em administração pública no Brasil (1952-1965). Revista Temas de Administração Pública, v. 2, n. 6, p. 1-9, 2011. 
COVRE, Maria L. M. A formação e a ideologia do administrador de empresas. São Paulo: Cortez, 1991.

CURADO, Isabela. Pesquisa historiográfica em administração: uma proposta metodológica. In: Anais ENANPAD... Campinas, 2001. p. 1-15.

D’ARAUJO, Maria C. Fundação Getulio Vargas: concretização de um ideal. Rio de Janeiro: Ed. Fundação Getulio Vargas, 1999.

DURHAM, Eunice R. Educação superior, pública e privada (1808-2000). In: BROCK, Colin; SCHWARTZMAN, Simon (Org.). Os desafios da educação no Brasil. Rio de Janeiro: Nova Fronteira, 2005. p. 197-240.

FGV/EBAP. A Escola Brasileira de Administração Pública e suas atividades em 1952 e 1953. Rio de Janeiro: 1954. Mimeografado.

FISCHER, Tânia. A formação do administrador brasileiro na década de 90: crise, oportunidade e inovações nas propostas de ensino. Rev. Adm. Pública, v. 27, n. 4, p. 11-20, out./dez. 1993.

FISCHER, Tânia. O ensino de administração pública no Brasil: os ideais de desenvolvimento e as dimensões de racionalidade (1948-1984). Tese (doutorado) — Faculdade de Economia e Administração, Universidade de São Paulo, São Paulo, 1984.

GAETANI, Francisco. O ensino de administração pública no Brasil em um momento de inflexão. Revista do Serviço Público, v. 50, n. 4, p. 92-114, out./dez. 1999.

GUERREIRO, Bruno et al. Formação profissional do administrador. Rev. Adm. Pública, v. 1, n. 2, p. 297-305, jul./dez. 1968.

JOHNSON, Jerald. Carreiras públicas e a nova classe profissional. Rev. Adm. Pública, v. 11, n. 4, p. 25-31, out./dez. 1977.

KEINERT, Ruben C. Perspectivas atuais do ensino de administração na Europa. Revista de Administração de Empresas, v. 26, n. 2, p. 65-70, abr./jun. 1986.

LORDELLO MELLO, Diogo. Curso de administração municipal. Cadernos de Administração Pública - EBAP, n. 18, 1954.

MACHADO, Marina B. Estágios para estudantes de administração: a experiência da EBAP. Rio de Janeiro: Ed. Fundação Getulio Vargas, 1970.

MACHADO, Marina B. O ensino de administração pública no Brasil. Rio de Janeiro: Ed. Fundação Getulio Vargas, 1966.

MARTINS, Carlos B. Surgimento e expansão dos cursos de administração no Brasil (1952-1983). Revista Educação e Sociedade, v. 12, n. 34, p. 663-676, jul. 1989.

MEZZOMO KEINERT, Tânia M. Análise das propostas dos cursos de administração pública no Brasil em função da evolução do campo de conhecimento. São Paulo: NPP — série relatório de pesquisa/ EAESP-FGV, 1996.

MEZZOMO KEINERT, Tânia M. Os paradigmas da administração pública no Brasil (1900-92). Revista de Administração de Empresas, v. 34, n. 3, p. 41-48, maio/jun. 1994. 
MINISTÉRIO DA EDUCAÇÃO E SAUUDE PÚBLICA. Obras completas de Rui Barbosa, Reforma do Ensino Secundário e Superior. Rio de Janeiro: Mesp, 1942.

MOITINHO, Álvaro P. Ciência da administração. Rio de Janeiro: Paulo de Azevedo, 1950.

MOURA CASTRO, Cláudio. O ensino de administração e seus dilemas: notas para o debate. Revista de Administração de Empresas, v. 21, n. 3, p. 58-61, jul./set. 1981.

MUÑOZ AMATO, Pedro. Introdução à administração pública. Rio de Janeiro: Ed. Fundação Getulio Vargas, 1958.

NICOLINI, Alexandre. Aprender a governar: a aprendizagem de funcionários públicos para as carreiras de Estado. Tese (doutorado) - Escola de Administração, Universidade Federal da Bahia. Salvador, 2007.

PACHECO, Regina S. Administração pública nas revistas especializadas — Brasil, 1995-2002. Revista de Administração de Empresas, v. 43, n. 4, p. 63-71, out./dez. 2003.

SANT'ANA, Vanya M. Os alunos de administração pública: formação escolar e prática profissional. Rev. Adm. Pública, v. 17, n. 4, p. 29-43, jul./ago. 1977.

SCHWARTZMAN, Simon; BOMENY, Helena; COSTA, Vanda. Tempos de Capanema. São Paulo: Paz e Terra, 2000.

SILVA, Benedicto. Gênesis do ensino de administração pública no Brasil. Cadernos de Administração Pública - EBAP, n. 49, 1958.

TOLEDO, Geraldo; TREVISAN, Gloria. O Departamento de Administração (1946-1969). In: CANABRAVA, Alice (Org.). A história da Faculdade de Economia e Administração da Universidade de São Paulo (1946-1981). São Paulo: FEA-USP, 1984.

VIEIRA, Paulo R. O ensino de administração em nível de graduação. Rev. Adm. Pública, v. 10, n. 3, p. 81-90, jul./set. 1976.

WAHRLICH, Beatriz. Evolução das ciências administrativas na América Latina. Rev. Adm. Pública, v. 13, n. 1, p. 31-68, jan./mar. 1979.

WAHRLICH, Beatriz. Formação em administração pública e de empresas: programas específicos ou integrados numa sociedade em desenvolvimento. Rev. Adm. Pública, v. 1, n. 2, p. 239-258, jul./ dez. 1967.

Fernando de Souza Coelho é doutor em administração pública pela EAESP-FGV e professor doutor da Escola de Artes, Ciências e Humanidades da Universidade de São Paulo (EACH-USP) no Curso de Graduação e no Programa de Mestrado em Gestão de Políticas Públicas e no Programa de Mestrado em Sistemas Complexos. E-mail: fernandocoelho@usp.br.

Alexandre Mendes Nicolini é doutor em administração pela UFBA e professor adjunto no Programa de Pós-Graduação em Administração da Universidade do Grande Rio (PPGA/Unigranrio). E-mail: alexandre. nicolini@unigranrio.com.br. 